\title{
Análise fisiológica em mudas de cafeeiro com cercosporiose submetida a diferentes lâminas de irrigação
}

\author{
Fernando Henrique Silva Garcia ${ }^{1}$, Alexis Fernando Matute Matute ${ }^{1}$, Larissa Cocato da Silva ${ }^{1}$, Hugo Rafael Bentzen \\ Santos $^{1}$, Deila dos Santos Botelho ${ }^{1}$, Marcelo Rodrigues ${ }^{1}$, João Paulo Rodrigues Alves Delfino Barbosa ${ }^{1}$
}

\begin{abstract}
${ }^{1}$ Universidade Federal de Lavras, Departamento de Biologia, Setor de Fisiologia Vegetal, Laboratório de Ecofisiologia Vegetal e Funcionamento de Ecossistemas, Caixa Postal 3037, 37200-000. Lavras MG, Brasil.

Autor para correspondência: Fernando Henrique Silva Garcia (fernandogarcia@usp.br).

Data de chegada: 28/09/2017. Aceito para publicação em: 15/03/2018.
\end{abstract}

$10.1590 / 0100-5405 / 185711$

\section{RESUMO}

Garcia, F.H.S.; Matute, A.F.M.; Silva, L.C.; Santos, H.R.B.; Botelho, D.S.B.; Marcelo Rodrigues, João Paulo R. A. D. Barbosa. Análise fisiológica em mudas de cafeeiro com cercosporiose submetida a diferentes lâminas de irrigação. Summa Phytopathologica, v.45, n.1, p.83-88, 2019.

Cercosporiose é uma das principais doenças que comprometem o crescimento de mudas de café por causar desfolha e redução no crescimento. A doença apresenta maior severidade quando o cafeeiro está submetido ao déficit hídrico. O uso de irrigação é uma alternativa para minimizar os danos causados pela doença. Objetivou-se neste trabalho avaliar o impacto da doença na fisiologia do cafeeiro em função da redução da lâmina de irrigação. As plantas foram submetidas a três lâminas de irrigação $(0.1,0.6$ e $1.2 \mathrm{~mm} \cdot \mathrm{dia}^{-1}$ ); inoculadas e não inoculadas com C. coffeicola, em delineamento inteiramente casualizado com 35 repetições, totalizando 210 unidades experimentais. As mudas de cafeeiro com cercosporiose apresentaram reduções no potencial hídrico mínimo e na fotossíntese em função da lâmina de irrigação, com excessão da lâmina de irrigação com $0,6 \mathrm{~mm} \cdot \mathrm{dia}^{-1}$. A atividade do sistema antioxidante foi superior nas mudas doentes apenas na maior irrigação. Os resultados comprovaram que a presença da doença incrementou o estresse hídrico nas mudas de café por reduzir o potencial hídrico e uso eficiente de água.

Palavras-chave: Sistema antioxidante, estresse hídrico, fotossíntese, déficit hídrico, trocas gasosas.

\section{ABSTRACT}

Garcia, F.H.S.; Matute, A.F.M.; Silva, L.C.; Santos, H.R.B.; Botelho, D.S.B.; Marcelo Rodrigues, João Paulo R. A. D. Barbosa. Physiological analysis in coffee seedlings showing brown eye spot under different irrigation levels. Summa Phytopathologica, v.45, n.1, p.83-88, 2019.

Abstract: Brown eye spot is one of the major diseases that affect coffee seedling growth for causing defoliation and reducing the plant growth. The disease severity is higher when the coffee plant is subjected to water deficit. Using irrigation is an alternative to minimize the damage caused by this disease. The aim of this study was to evaluate the impact of this disease on the physiology of coffee plants as a function of the reduction in the irrigation level. The plants were subjected to three irrigation levels $(0.1,0.6$ and $1.2 \mathrm{~mm}$ day $\left.^{-1}\right)$, inoculated and not inoculated with Cercospora coffeicola, in a completely randomized design with 35 replicates, totaling 210 experimental units. Coffee seedlings showing brown eye spot presented reductions in the minimum water potential and in photosynthesis as a function of the lower irrigation level, except for the irrigation level $0.6 \mathrm{~mm}$.day ${ }^{-1}$. The activity of the antioxidant system in diseased seedlings was only higher under higher irrigation levels. Results proved that the presence of the disease increased water stress in coffee seedlings for reducing both water potential and efficient water use.

Keywords: Antioxidant system, water stress, photosynthesis, water deficit, gas exchange.

Em condições de campo, as plantas estão expostas a um conjunto de fatores adversos de origem biótica e abiótica que reduzem a produtividade nas culturas agrícolas. O déficit hídrico é um dos principais fatores limitantes que resultam na queda de produção de alimentos no mundo (11). No Brasil, as regiões de cultivo de café não irrigado, a limitação hídrica causaram reduções na produtividade dos cafeeiros por proporcionar uma diminuição na taxa fotossintética e um menor acúmulo de açúcares para ser destinado para formação do fruto (7).

Na fase de muda, o cafeeiro é sensível a limitação hídrica, plantas no estado de déficit hídrico apresentam desfolha e redução na taxa de crescimento. Além disso, o déficit hídrico também leva a perda da turgescência foliar e reduz a atividade fotossintética, implicando em uma menor disponibilidade de carbono para ser investido no crescimento da planta $(5,6)$. Desta forma, o déficit hídrico pode tornar a planta susceptível a outros fatores adversos, como a infecção de Cercospora coffeicola nas folhas (20).

C. coffeicola é um dos principais patógenos na cultura do cafeeiro que causa a doença chamada cercosporiose, responsável por reduzir em até $40 \%$ a produtividade do cafeeiro (21). As condições ambientais que favorecem a germinação dos esporos do fungo são temperatura de $17^{\circ} \mathrm{C}$ e luminosidade de $320 \mu \mathrm{mol} \mathrm{m}^{-2} \mathrm{~s}^{-1}$ (21). Os esporos germinam 
na folha e em seguida produzem hifas que penetram nos estômatos na face abaxial da folha, colonizando as camadas subestomáticas (22). A infecção do fungo promove alterações no metabolismo fotossintético da planta (10), causando prejuízos diretos na produção das mudas no viveiro devido ao aumento no tempo na formação das mudas e a produção de mudas com menor qualidade.

A disponibilidade hídrica no solo está diretamente associado com a severidade da cercosporiose no cafeeiro. Plantas de café submetidas a irrigação apresentaram uma menor ocorrência de cercosporiose, enquanto em condição de déficit hídrico há um aumento na severidade da doença $(8,20)$. Entretanto, a presença da doença no cafeeiro submetido ao déficit hídrico incrementou a taxa fotossintética (10). Ainda é desconhecido se o incremento na fotossíntese nas plantas doentes seria proporcionado por um efeito benéfico da infecção do patógeno ou ser proveniente de um transtorno fisiológico na planta. Quando a planta está submetida a mais de um fator adverso, as alterações fisiológicas desencadeadas por um estresse inicial poderão minimizar ou intensificar os danos de outro estresse na planta $(19,5)$.

A atividade do sistema antioxidante é uma das ferramentas para avaliar o estado de estresse das plantas, a partir do combate das espécies reativas de oxigênio (EROS). As EROS podem ser produzidas nos cloroplastos, mitocôndrias e peroxisossomo e sua taxa irá variar de acordo com estado fisiológico da planta. Em baixas concentrações as EROS atuam como sinalizador intercelular, participando da regulação de diversos processos fisiológicos em resposta aos estímulos ambientais (3). Contudo, o excesso de EROS na célula pode resultar em danos nas estruturas celulares e biomoléculas, como a peroxidação lipídica, desnaturação de proteínas e mutações no DNA(17). Contudo, as plantas possuem um sistema antioxidante enzimático e não enzimático que combatem o excesso de EROS produzido por seu metabolismo. Enzimas como dismutase do superóxido (SOD), catalase (CAT) e peroxidase do ascorbato (APX) são responsáveis por eliminar o excesso de EROS (17). Ainda faltam esclarecimentos sobre as alterações fisiológicas causadas pela cercosporiose associado a uma menor lâmina de irrigação. Deste modo, objetivou-se neste estudo verificar se a presença de cercosporiose nas mudas de café poderá atenuar ou intesificar o estresse hídrico nas plantas com a redução lâmina de irrigação.

\section{MATERIAL E MÉTODOS}

\section{Material vegetal}

O experimento foi conduzido em casa de vegetação, utilizando mudas de cafeeiro cv. Mundo Novo 376/4 com seis meses de idade. As mudas foram cultivadas em sacos de polietileno $(24,0 \times 13,5 \mathrm{~cm})$ com volume de 3,5 litros de substrato. As plantas foram adubadas com solução nutritiva de Hoagland e Arnon (13) e irrigadas por sistema de gotejamento até atingirem a capacidade de campo. As condições ambientais na casa de vegetação foram monitoradas através do sensor datalogger, sendo registrados a temperatura, umidade relativa e o déficit de pressão de vapor durante o dia.

$\mathrm{O}$ experimento foi conduzido em delineamento inteiramente casualizado, em esquema fatorial $3 \times 2$, com três lâminas de irrigação (0.1, 0.6 e $\left.1.2 \mathrm{~mm} \cdot \mathrm{dia}^{-1}\right)$, associado à inoculação do fungo Cercospora coffeicola (plantas inoculadas e não inoculadas) com 35 repetições por tratamento, totalizando 210 plantas. As avaliações fisiológicas nas plantas foram realizadas aos 12 dias (T1) e 36 dias (T2) após a implantação dos tratamentos. Os dados obtidos foram inicialmente avaliados pelo teste de normalidade Shapiro-Wilk e posteriormente foi realizado uma análise de variância dos dados. Diferença entre os tratamentos foram obtidas a partir do erro padrão $( \pm \mathrm{EP})$.

\section{Obtenção de esporos de cercospora coffeicola}

Para obtenção de esporos de Cercospora coffeicola utilizou-se a metodologia proposta por Souza com algumas adaptações (22). Oito discos de micélio (0,5 mm de diâmetro) do isolado CML 2984 foram retirados da borda da colônia do fungo e transferidos para $20 \mathrm{ml}$ de meio V8 (100 ml de V8 ${ }^{\circledR}$ plus $900 \mathrm{ml}$ de água destilada) em erlenmeyer de $25 \mathrm{ml}$ os quais foram continuamente agitados $(120 \mathrm{rpm})$ a $25^{\circ} \mathrm{C}$. Após 4 dias, o conteúdo do erlenmeyer foi vertido em placas de petri contendo meio com ágar $1,5 \%$. As placas foram mantidas abertas em incubadora tipo BOD a $40 \mathrm{~cm}$ de distância da lâmpada de luz fluorescente de $40 \mathrm{~W}$, para fornecer $165 \mu \mathrm{mol} \mathrm{s}^{-1} \mathrm{~m}^{-2}$ para promover o crescimento do fungo. A condição de incubação foi colocada na temperatura de $25^{\circ} \mathrm{C}$ e fotoperíodo de 12 horas. Após a desidratação do meio de cultura (aproximadamente 4 dias de incubação), foi adicionado em cada placa $10 \mathrm{~mL}$ de água destilada esterilizada para a remoção dos esporos com o auxílio da alça de Drigaslki. O líquido obtido foi filtrado em gaze para a retirada dos resíduos e a esporulação foi quantificada em câmara de Neubauer. A suspensão utilizada na inoculação foi calibrada para a concentração de $2 \times 10^{4}$ conídios $\mathrm{mL}^{-1} \mathrm{e}$ aplicada nos três primeiros pares de folhas da planta utilizando um pulverizador 'De Vilbiss' $n^{\circ} 15$.

\section{Parâmetros fisiológicos}

O estado hídrico das plantas foi monitorado a partir da avaliação do seu potencial hídrico, utilizando a câmera de pressão de Scholander para determinação do potencial hídrico máximo $\left(\Psi_{\mathrm{pd}}\right.$ máximo) entre os horários 3:00 a 5:00h da manhã e potencial hídrico mínimo ( $\Psi_{\mathrm{md}}$ mínimo) entre os horários 12:00 a 14:00h da tarde.

A assimilação de $\mathrm{CO}_{2}(A)$, condutância estomática $\left(g_{s}\right)$ e transpiração $(E)$ foram aferidas entre 9:00 e 11:00 horas, utilizando um analisador portátil de gás infravermelho (IRGA modelo LI-6400 $\mathrm{xt}$ ), com intensidade luminosa de $1000 \mu \mathrm{mol} \mathrm{m} \mathrm{m}^{-1}$ e fluxo $400 \mathrm{umol}$ $\mathrm{CO}_{2} \mathrm{~mol}^{-1}$ de ar do ambiente. Determinou-se a eficiência do uso da água (EUA), e eficiência do uso da luz (EUL), a partir das equações: $\mathrm{EUA}=A / E ; \mathrm{EUL}=A / D F F F A$.

\section{Atividade do sistema antioxidante}

A quantificação da atividade das enzimas dismutase do superóxido (SOD), catalase (CAT) e peroxidase do ascorbato (APX) foram realizadas em tecidos foliares conforme proposto por $(12,15)$. As amostras foram obtidas utilizando almofariz e nitrogênio líquido, contendo $60 \mathrm{mg}$ de PVPP e 1,5 mL usando os seguintes meios de extração: para SOD (100 mM de tampão de fosfato de potássio, $\mathrm{pH} 7,8$; 0,1 mM EDTA e 0,1\% Triton X-100); para CAT (100 mM de tampão de fosfato de potássio, pH 7,8 e 0,1 mM EDTA) e para APX (50 mM de tampão de fosfato de potássio, $\mathrm{pH}$ 7,8 e $1 \mathrm{mM}$ de ascorbato).

Para medir a atividade da SOD, foi adicionada $10 \mu 1$ de alíquota do extrato de proteína com tampão de incubação $(100 \mu 1$ de fosfato de potássio $100 \mathrm{mM}$, pH 7,8, $40 \mu \mathrm{l}$ de metionina $70 \mathrm{mM}, 3 \mu \mathrm{L}$ EDTA $10 \mu \mathrm{M}, 31 \mu \mathrm{L}$ de água, $15 \mu \mathrm{L}$ de NBT a $1 \mathrm{mM}$ e $2 \mu \mathrm{L}$ de riboflavina $0,2 \mathrm{mM}$ ). Os tubos foram iluminados por 7 minutos com lâmpada fluorescente de $20 \mathrm{~W}$. O branco foi feito apenas com tampão de incubação sem a adição da alíquota da amostra. A atividade da SOD foi determinada pela inibição da fotoredução do azul de nitrotetrazólio (12). A leitura foi feita em $560 \mathrm{~nm}$, sendo calculado a atividade da enzima através da equação: \% inibição $=($ A560 amostra com enzima extraída - A560 controle sem extrato da enzima). 
Para medir a atividade da CAT, foi adicionado $10 \mu \mathrm{L}$ da alíquota do extrato de proteína com $170 \mu \mathrm{L}$ tampão de incubação $(90 \mu \mathrm{L}$ de fosfato de potássio $200 \mathrm{mM}, \mathrm{pH} 7,0,71 \mu \mathrm{L}$ de água e $9 \mu \mathrm{L}$ de peróxido de hidrogênio $250 \mathrm{mM}$, incubados em $28^{\circ} \mathrm{C}$ ). A atividade enzimática foi determinada pelo monitoramento do consumo de peróxido de hidrogênio através do decréscimo da absorbância $240 \mathrm{~nm}$. O coefíciente de extinção molar utilizado foi $36 \mathrm{mM}^{-1} \mathrm{~cm}^{-1}$.

Para medir a atividade da APX, foi adicionado $10 \mu \mathrm{L}$ de extrato de proteína com $170 \mu \mathrm{L}$ de tampão de incubação $(90 \mu \mathrm{L}$ de fosfato de potássio $200 \mathrm{mM}, \mathrm{pH}$ 7.0, $9 \mu \mathrm{L}$ ácido ascórbico $10 \mathrm{mM}, 62 \mu \mathrm{L}$ de água e $9 \mu \mathrm{L}$ de peróxido de hidrogênio) (16). O coeficiente de extinção molar foi $2.8 \mathrm{mM}^{-1} \mathrm{~cm}^{-1}$. Atividade da APX foi determinada por meio do monitoramento da taxa de oxidação do ascorbato em $290 \mathrm{~nm}$ avaliado por $15 \mathrm{~s}$ durante 3 minutos.

\section{RESULTADOS E DISCUSSÃO}

Os dados de temperatura e déficit de pressão de vapor $(D P V)$ registrados na casa de vegetação não apresentaram diferença significativa durante o período de condução do experimento. Com 12 dias de inoculação (T1), os valores de temperatura e $D P V_{\text {atm }}$ médio na casa de vegetação foram de $44,0 \pm 3,9{ }^{\circ} \mathrm{C}$ e $6,5 \pm 2,0 \mathrm{kPa}$. Com 36 dias após a inoculação (T2) a média de temperatura e pressão de vapor na casa de vegetação foram de $36,0 \pm 5,2{ }^{\circ} \mathrm{C}$ e $3,6 \pm 2,5 \mathrm{kPa}$.

As mudas de café decresceram seu $(\mathrm{p}<0,05)$ potencial hídrico máximo $\left(\Psi_{p d}\right)$ e mínimo $\left(\Psi_{m d}\right)$ em função da lâmina de irrigação e da presença de cercosporiose. Nas mudas de cafeeiro com lâmina de irrigação $1,2 \mathrm{~mm} \cdot \mathrm{dia}^{-1}$, observou-se que a presença do patógeno decresceu o $\Psi_{p d}-0,75 \mathrm{Mpa}$ em relação ao controle com $\Psi_{p d}-0,45 \mathrm{Mpa}$ (Figura 1A). Com a redução na lâmina de irrigação para $0,6 \mathrm{~mm} \cdot \mathrm{dia}^{-1}$ e $0,3 \mathrm{~mm} \cdot \mathrm{dia}^{-1}$, houve menor $\Psi_{\mathrm{md}}$ nas mudas de cafeeiro doentes no segundo tempo de avaliação $\mathrm{O}$ aumento do tempo de exposição nas plantas aos dois fatores adversos reduziu o $\Psi_{p d}$ da planta (Figura 1).

Os valores de assimilação $\mathrm{CO}_{2}(A)$, condutância estomática $(g s)$ e transpiração $(E)$ decresceram proporcionalmente $(\mathrm{p}<0,05)$ com a redução do $\Psi_{p d}$ foliar (Figura 2). As mudas com lâmina de irrigação 1,2 mm.dia ${ }^{-1}$ não exibiram diferença em função da presença do patógeno. Com a redução lâmina de irrigação para $6 \mathrm{~mm} \cdot \mathrm{dia}^{-1}$, as plantas doentes exibiram superior $A$ e $E$ do que as plantas sadias nos dois tempos observados. $\mathrm{O}$ aumento proporcionado pela doença nos valores $A$ e $E$ foram causados pela maior $g s$ exibido pelas plantas doentes. Com lâmina de irrigação de $0,3 \mathrm{~mm} \cdot \mathrm{dia}^{-1}$ as plantas doentes obtiveram menor taxa fotossintética que as plantas sadias apenas no primeiro tempo de avaliação. Mesmo havendo superior $A$ que as plantas doentes, as plantas sadias exibiram menor gs. O maior valor de $A$ nas plantas sadias não foi causado pela gs. A taxa de transpiração foi superior nas plantas doentes em relação as plantas sadias apenas no segundo tempo.

O uso eficiente da luz (EUL) obteve diferença entre as lâminas de irrigação em função da presença do patógeno $(\mathrm{p}<0,05)$. As mudas doentes exibiram maior EUL que as plantas sadias sobre lâmina de irrigação $0,6 \mathrm{~mm} \cdot$ dia $^{-1}$. Entretanto com a diminuição da irrigação para $0,3 \mathrm{~mm} \cdot \mathrm{dia}^{-1}$ as mudas sadias obtiveram maior valor EUL apenas na primeira avaliação. O uso eficiente da água (EUA) foi superior (p $<0,05)$ nos tratamentos com ausência de C. coffeicola em todas as lâminas de irrigação (Figura 3). O menor EUA nas plantas doentes foi proporcionado pela menor relação $A / g s$.

As mudas de café submetidas a uma menor lâmina de irrigação, apresentaram redução da taxa fotossintética devido a menor gs (6).

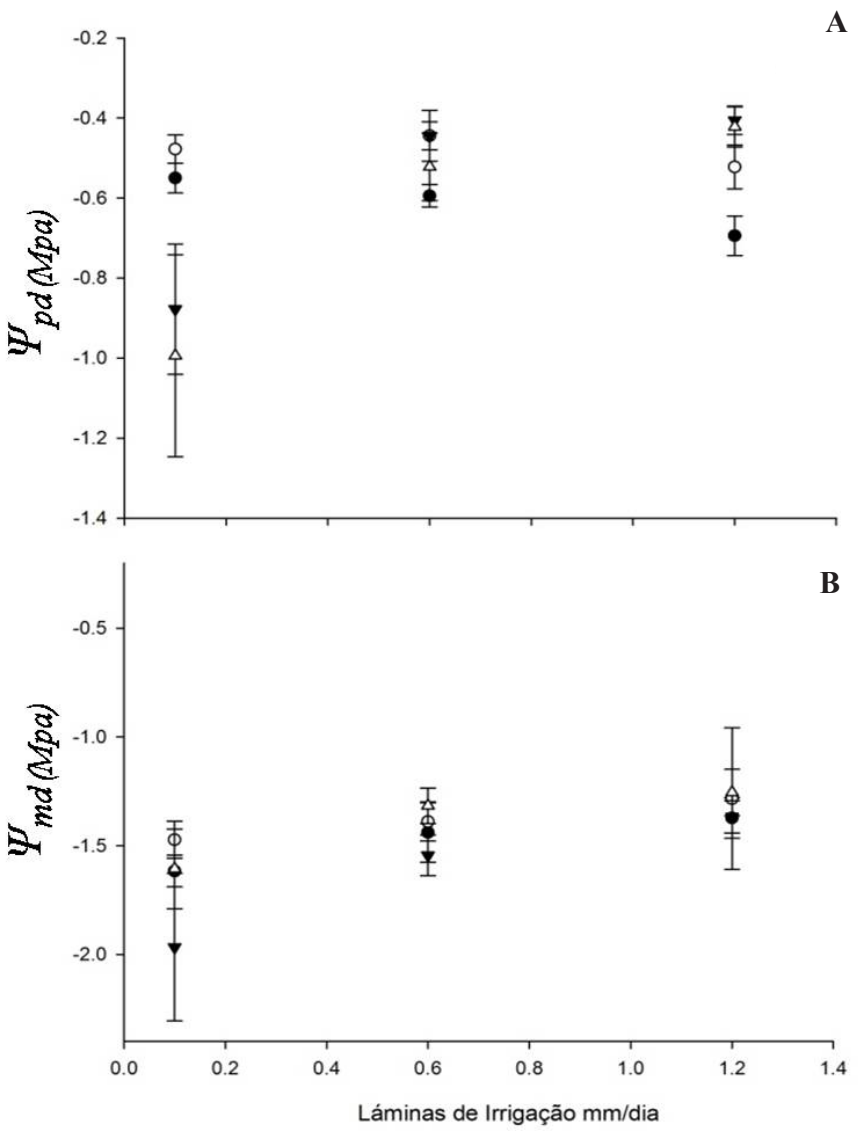

Figura 1. Potencial hídrico foliar de mudas de cafeeiro (Coffea arabica) submetido a diferentes regimes hídricos, com presença e ausência de inoculação com C. coffeicola. A) máximo $\left(\Psi_{p d}\right)$; B) mínimo $\left(\Psi_{m d}\right)$. Diferença significativa entre os tratamentos $\pm \stackrel{p P}{E P}(\mathrm{p}=0,05)$, não diferiram quando houve sobreposição dos erros entre as médias. Legenda: $\bullet$ inoculado T1 $\circ$ não inoculado T1, $\boldsymbol{\nabla}$ inoculado T2 e $\Delta$ não inoculado T2.

Com exceção das mudas doentes irrigadas com $0,6 \mathrm{~mm} \cdot \mathrm{dia}^{-1}$, que apresentaram maior taxa fotossintética nos dois tempos avaliados em relação as mudas sadias. A maior condutância estomática encontrada nas mudas doentes pode ser causada pela presença das hifas do fungo penetrarem nos estômatos na face abaxial da folha, (22), que consequentemente formam uma barreira física ao fechamento estomático. Desta forma, aumento da fotossíntese nas plantas infectadas com C. coffeicola com lâmina de irrigação de $0,6 \mathrm{~mm} \cdot \mathrm{dia}^{-1}$, pode estar relacionado com o aumento difusão de $\mathrm{CO}_{2}$, proporcionado pela maior condutância estomática produzida pela presença do patógeno (18). Resultados similares também foram encontrados em outros trabalhos com café (10) e também em outras culturas (1), onde a infecção dos fungos aumentaram a condutância estomática e a taxa fotossintética. $\mathrm{O}$ aumento da difusão de $\mathrm{CO}_{2}$ associado ao melhor uso da energia para redução do $\mathrm{CO}_{2}$ levou ao aumento da fotossíntese nas plantas doentes.

Entretanto as plantas doentes com lâmina de irrigação $0,3 \mathrm{~mm} \cdot$ dia $^{-1}$ exibiram em T1 uma menor $A$ e maior $g s$ e $E$. Desta forma, em condições moderadas de déficit hídrico a doença provoca aumento da taxa fotossintética por aumentar gs. Contudo, com menor lâmina de irrigação, a cercosporiose aumenta o estresse hídrico na planta. As plantas doentes exibiram menor potencial hídrico em decorrência de um menor uso eficiente da água. 


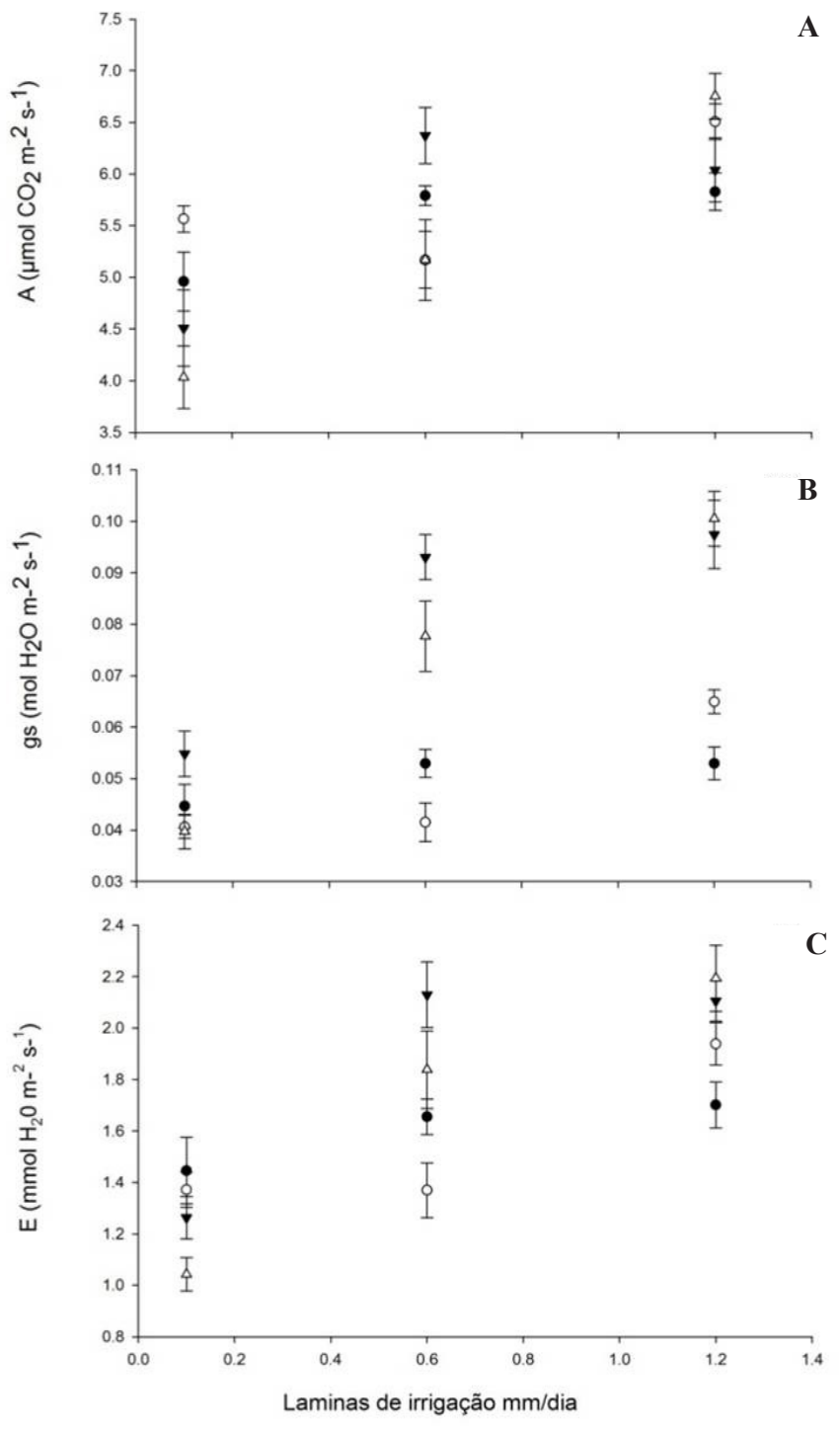

Figura 2. Trocas gasosas na folhas de cafeeiro arábica submetido a diferentes regimes hídricos, com presença e ausência de inoculação com C. coffeicola. A) assimilação de $\mathrm{CO}_{2}(A)$; B) condutância estomática $(g s)$; C) transpiração $(E)$. Diferença significativa entre os tratamentos foram obtidas através $\pm \mathrm{EP}(\mathrm{p}=0,05)$. Os tratamentos não diferiram quando houve sobreposição dos erros entre as médias. Legenda: inoculado T1 $\circ$ não inoculado T1, $\boldsymbol{\nabla}$ inoculado T2 e $\Delta$ não inoculado $\mathrm{T} 2$.

Para comprovar a nível bioquímico que a infecção C. coffeicola, aumenta o estado de estresse na planta em função da lâmina de irrigação, foi avaliado a atividade do sistema antioxidante nas mudas de café, através da atividade SOD e CAT e APX. A atividade da SOD, CAT e APX (Figura 4A, 4B e 4C) diferiram apenas em função da presença do patógeno.

As mudas de café submetidas a $1,2 \mathrm{~mm} \cdot \mathrm{dia}^{-1}$ apresentaram maior atividade da SOD na presença $C$. coffeicola a partir da segunda avaliação. Já a atividade da APX foi inferior no tratamento com 1,2 mm.dia ${ }^{-1}$ com ausência do patógeno. Nas mudas de café submetidas a irrigação com $0,6 \mathrm{~mm} \cdot \operatorname{dia}^{-1}$ e $0,3 \mathrm{~mm} \cdot \operatorname{dia}^{-1}$ não houve diferença na atividade da SOD. A atividade da CAT foi superior nas mudas doentes submetidas as lâminas de irrigação 1,2 e $0,6 \mathrm{~mm} \cdot \mathrm{dia}^{-1}$ no segundo tempo

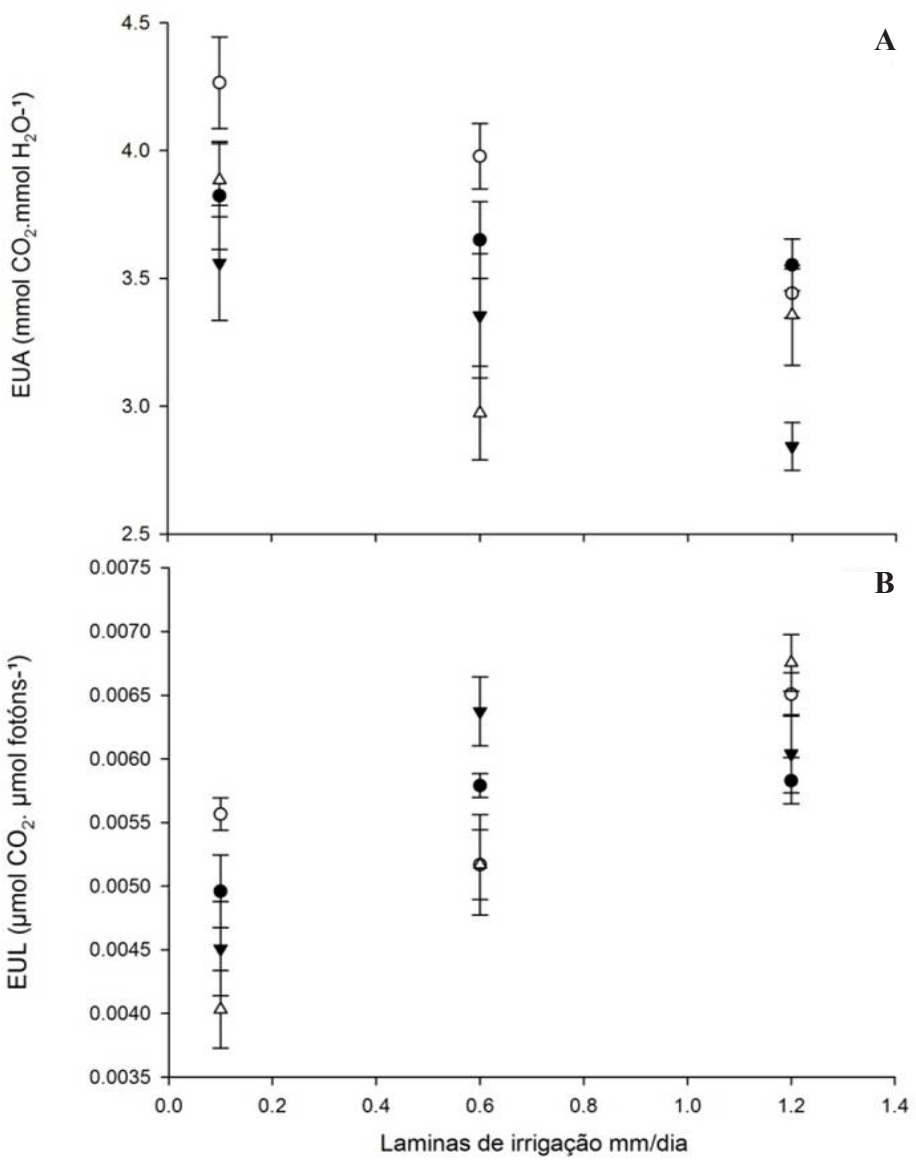

Figura 3. Eficiência no uso da água (A) e no uso da luz (B) em mudas de cafeeiro arábica submetido a diferentes regimes hídricos, com presença e ausência de inoculação com $C$. coffeicola. Diferença significativa entre tratamento foi feito a partir $\pm \mathrm{EP}(\mathrm{p}=0,05)$, tratamentos não diferiram quando houve sobreposição dos erros nas médias.Legenda: inoculado T1 $\circ$ não inoculado $\mathrm{T} 1, \boldsymbol{\nabla}$ inoculado T2 e $\Delta$ não inoculado $\mathrm{T} 2$.

de avaliação. Na lâmina de $0,3 \mathrm{~mm} \cdot \mathrm{dia}^{-1}$ não foi observado diferença na atividade de CAT entre os tratamentos.

A redução da lâmina de irrigação aplicada nas mudas de café provocou um aumento na atividade CAT e APX, indicando um aumento do estresse nas plantas com menor lâmina de irrigação. As mudas de café sob um menor regime hídrico incrementaram a atividade da SOD e CAT (4). Pois o aumento na atividade das enzimas é resultado da maior formação de espécies reativas de oxigênio geradas por seu metabolismo (15).

Neste trabalho foi verificado que as plantas doentes exibiram maior atividade da SOD e APX apenas na maior lâmina de irrigação durante o segundo tempo de avaliação. Além disso as mudas doentes com lâmina de irrigação de $0,6 \mathrm{~mm} \cdot$ dia $^{-1}$, exibiram menor potencial hídrico e maior a atividade da CAT. Esses resultados demonstram que a presença do patógeno potencializa o estresse na planta (Figura 4). Andrade et al. (2) verificaram que cafeeiro infectado com duas raças de C. coffeicola elevaram a atividade da SOD e CAT ao longo do tempo. O mesmo resultado ocorreu no café infectado com Hemileia vastatrix, observando um aumento na atividade de CAT nas mudas de café (14). Portanto, a presença de cercosporiose na muda de café proporcionou o aumento atividade das enzimas SOD e APX. Contudo, não foi verificado uma 

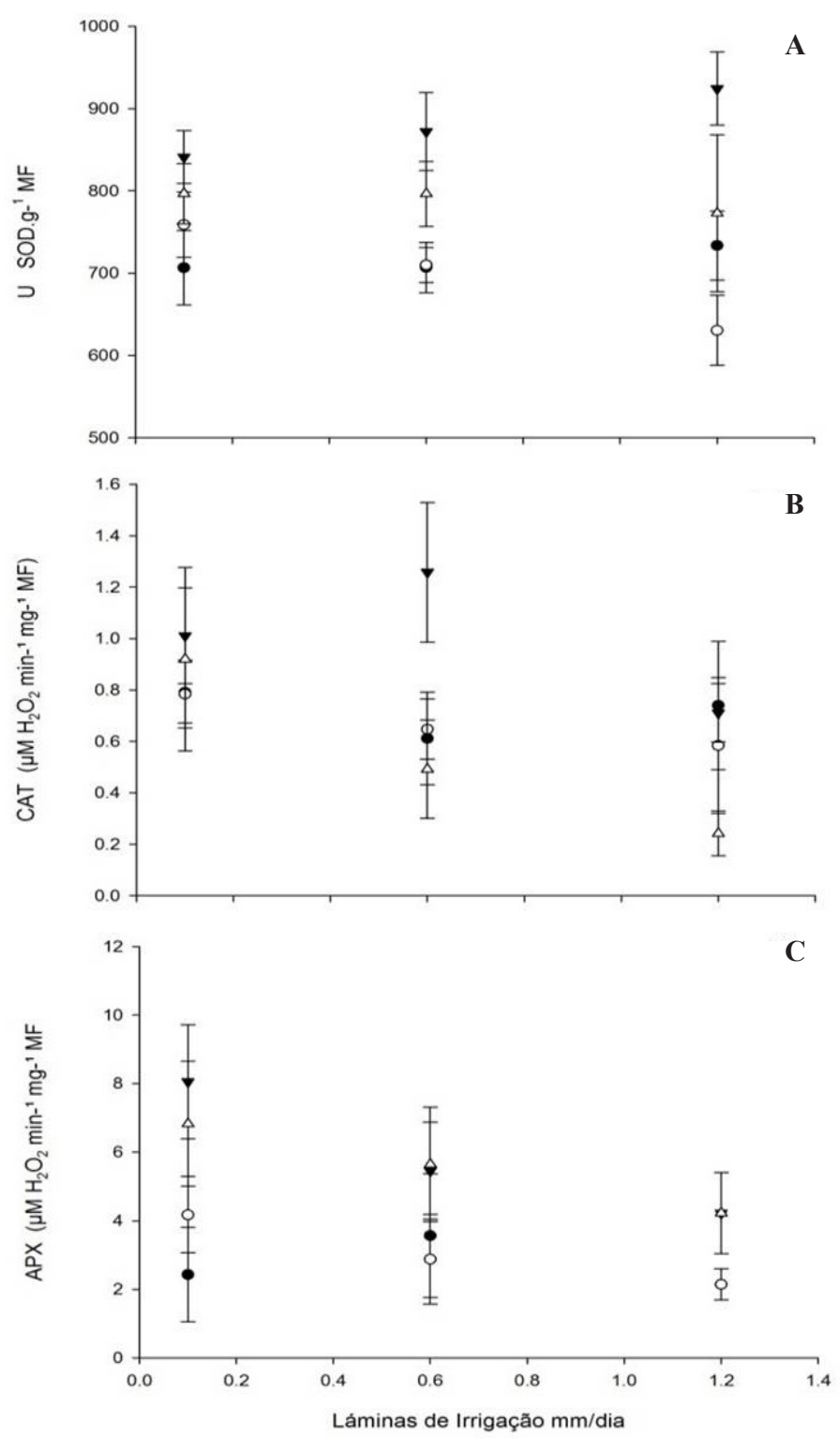

Figura 4. Atividade enzimática do sistema antioxidante foliar de cafeeiro arábica submetido a diferentes regimes hídricos, com presença e ausência de patógeno. Diferença significativa entre tratamento foi feito a partir $\pm \mathrm{EP}(\mathrm{p}=0,05)$, tratamentos não diferiram quando houve sobreposição dos erros entre as médias. Legenda: $\bullet$ inoculado T1 ○ não inoculado T1, $\boldsymbol{\nabla}$ inoculado T2 e $\Delta$ não inoculado T2.

correlação do aumento na atividade das enzimas um em função da presença de cercóspora nas mudas de café em detrimento da redução na lâmina de irrigação.

Nosso estudo comprovou que a presença de Cercospora coffeicola potencializou o estresse hídrico, pela planta doente apresentar maior condutância estomática em condições de baixa lâmina de irrigação que resultou no decréscimo do potencial hídrico e no menor uso eficiente da água da planta.

\section{AGRADECIMENTO}

O presente trabalho foi realizado com apoio da Coordenação de Aperfeiçoamento de Pessoal de Nível Superior - Brasil (CAPES) - Código de Financiamento 001 e pelo Conselho Nacional de Desenvolvimento Científico e Tecnológico (CNPQ) pela concessão da bolsa PROCESSO 169260/2017-8. Agradecemos Joel, Odorêncio e Dartagnan pelo suporte técnico nos experimentos.

\section{RERERÊNCIAS}

1. Allègre, M.; Daire, X.; Héloir, M.C; Trouvelot, S.; Mercier, L.; Adrian, M.; Pugin, A. Stomatal deregulation in Plasmopara viticola-infected grapevine leaves. New Phytologist, Lancaster, v.173, n.4, p.832-840, 2007.

2. Andrade, C.C.L.; Vicentin, R.P.; Costa, J.R.; Perina, F.J.; Resende, M.L.V.; Alves, E. Alterations in antioxidant metabolism in coffee leaves infected by Cercospora coffeicola. Ciência Rural, Santa Maria, v.46, n.10, p.1764$1770,2016$.

3. Baxter, A.; Mittler, R.; Suzuki, N. ROS as key players in plant stress signalling. Journal of Experimental Botany, Lancaster, v.65, n.5, p.12291240, 2014.

4. Cai, Z.Q.; Chen, Y.J.; Guo, Y.H.; Cao, K.F. Responses of two field-grown coffee species to drought and re-hydration. Photosynthetica, Dordrecht, v.43, n.2, p.187-193, 2005.

5. Chaves, M.M; Pereira, J.S.; Maroco, J.; Rodrigues, M.L.; Ricardo, C.P.P.; Osório, M.L.; Carvalho, I.; Faria, T.; Pinheiro, C. How plants cope with water stress in the field? Photosynthesis and growth. Annals of Botany, Oxford, v.89, n.7, p.907-916, 2002.

6. Chaves, M.M.; Flexas, J.; Pinheiro, C. Photosynthesis under drought and salt stress: regulation mechanisms from whole plant to cell. Annals of Botany, Oxford, v.103, n.4, p.551-560, 2009. http://www.conab.gov.br/ OlalaCMS/uploads/arquivos/14_05_15_09_04_55_boletim_maio-2014. pdf. Acessed: 24 Maio 2017

7. Custódio, A.A.P.; Pozza, E.A.; Custódio, A.A.P.; Souza, P.E. Lima, L.A.; Silva, A.M. Effect of Center-pivot irrigation in the rust and brown eye spot of Coffee. Plant Disease, Saint Paul, v.98, n.7, p.943-947, 2014.

8. Deuner, S.; Alves, J.D.; Zanandrea, I.; Goulart, P.F.P.; Silveira, N.M.; Henrique, P.C.; Mesquita, A.C. Stomatal behavior and components of the antioxidative system in coffee plants under water stress. Scientia Agricola, Piracicaba, v.68, n.1, p.77-85, 2011.

9. Botelho, D.M.S.; Pozza, E.A.; Alves, E.; Furtini Neto, A. E.; Barbosa, J.P.R.A.D.; Castro, D.M. Aspectos anatômicos e fisiológicos de mudas de cafeeiro (Coffea arabica L.) com cercosporiose (Cercospora coffeicola Berk. \& Cook.) adubadas com ácido silícico. Coffee Science, Lavras, v.4, n.2, p.93-99, 2009. www.fao.org/nr/aboutnr/nrl>. Acesso em: 15 dez. 2015.

10. Giannopolitis, C.N.; Ries, S.K. Superoxide dismutases I. OCVurrence in higher plants. Plant Physiology, Rockville, v.59, n.2, p.309-314, 1977.

11. Hoagland, D.R.; Arnon, D.I. The water-culture method for growing plants without soil. 2nd ed. California Agricultural Experiment Station, Gaisneville, v.347, 1950.

12. Júnior, J.H.; Zambolim, L.; Aucique-Pérez, C.E; Resende, R.S.; Rodrigues, F.A. Photosynthetic and antioxidative alterations in coffee leaves caused by epoxiconazole and pyraclostrobin sprays and Hemileia vastatrix infection. Pesticide Biochemistry and Physiology, California, v.123, p.31-39, 2015.

13. Lima, A.L.S.; DaMatta, F.M.; Pinheiro, H.A.; Totola, M.R.; Loureiro, M.E. Photochemical responses and oxidative stress in two clones of Coffea canephora under water deficit conditions. Environmental and Experimental Botany, Amsterdam, v.47, n.3, p.239-247, 2002.

14. Nakano, Y.; Asada, K. Hydrogen peroxide is scavenged by ascorbate-specific peroxidase in spinach chloroplasts. Plant and Cell Physiology, Oxford, v. 22, n.5, p.867-880, 1981.

15. Noctor, G.; Mhamdi, A.; Foyer, C.H. Oxidative stress and antioxidative systems: recipes for suCVessful data collection and interpretation. Plant, Cell \& Environment, Logan, v.39, n.5, p.1140-1160, 2016.

16. Porcar-Castell, A.; Tyystjärvi, E.; Atherton, J.; van der Tol, C.; Flexas, J.; 
Pfündel, E.E.; Moreno, J.; Frankenberg, C.; Berry, J.A. Linking chlorophyll a fluorescence to photosynthesis for remote sensing applications: mechanisms and challenges. Journal of Experimental Botany, Lancaster, v.65, n. 15, p.4065-4095, 2014.

17. Rejeb, K.B.; Abdelly, C.; Savouré, A. How reactive oxygen species and proline face stress together. Plant Physiology and Biochemistry, Paris, v.80, p.278-284, 2014.

18. Santos, F.D.S.; Souza, P.E.; Pozza, E.A. Epidemiologia da cercosporiose em cafeeiro fertirrigado. Summa Phytopathologica, Jaboticabal, v.30, n.1, p.31-37, 2004.

19. Silva, M.G.; Pozza, E.A.; Lima, C.V.R.V.; Fernandes, T.J. Temperature and light intensity interaction on Cercospora coffeicola sporulation and conidia germination. Ciência e Agrotecnologia, Lavras, v.40, n.2, p. 198-204, 2016.

20. Souza, A.G.C.; Rodrigues, F.A.; Maffia, L.A.; Mizubuti, E.S.G. Infection process of Cercospora coffeicola on coffee leaf. Journal of Phytopathology, Berlin, v.159, n.1, p.6-11, 2011. 